\title{
Low Power Laser Therapy (LPLT) in the Treatment of Radiation Therapy (RT) Induced Oral Mucositis (OM).
}

\author{
Magda Mostafa', M. Abdelrahman' ${ }^{1}$, Wesam A. Elshrief ${ }^{1}$, Awatef L. ${ }^{2}$, Soheir S. ${ }^{2}$ and H. Awadey \\ ${ }^{1}$ Kasr Alaini Center of Clinical Oncology and Nuclear Medicine (NEMROCK)-Faculty of Medicine, \\ ${ }^{2}$ Department of Basic Science, Faculty of Physical Therapy, Cairo University.
}

\begin{abstract}
Objectives: This prospective phase II trial aiming at evaluation of feasibility \& tolerability of LPLT in the treatment of RT induced OM in Head \& Neck (H\&N) cancer.

Patients and Methods: Fourty patients with pathologically proven squamous cell carcinoma of H\&N were included with any grade of OM while receiving RT. Patients with double malignancy, re-irradiation \& severe collagen vascular disease were excluded. The LASER apparatus used in this study was gallium arsenide (GAAS) LTU-904 with power output 5w and pulse length $200 \mathrm{~ns}$. The mucositis grade was assessed using the Radiation Therapy Oncology Group (RTOG) assessment scale.

Results: There was a significant reduction in the mean RTOG assessment scale between pre and post treatment values by $54.65 \%$ from $2.47 \pm 0.64$ to $1.12 \pm 0.33$ (with $P$-value $=0.0001$ ). Reduction in the mean RTOG scale was seen in both sexes (males $=51.06 \%$, females $=57.69 \%)$, in smokers $(51.51 \%)$, non-smokers $(56.58 \%)$, patients older than 55 years $(52.04 \%) \&$ younger patients $(56 \%)$. Univariate analysis showed no significant effect for age. Multivariate analysis showed that female sex gained more benefit $(P$-value $=0.045)$. Patients tolerated the LPLT treatment without any adverse effect or reaction.

Conclusion: LPLT is a feasible well tolerated treatment for RT induced OM with better results seen in non smokers \& females, female sex was the only independent prognostic factor in a multivariate analysis. Further phase III study is recommended on a large number of cases.
\end{abstract}

Key words: Low Power LASER therapy, radiation therapy, oral mucositis.

Corresponding Author: M. Abdelrahman.

E-mail: mohamedonco@yahoo.com

\section{INTRODUCTION}

Head and neck $(\mathrm{H} \& \mathrm{~N})$ cancers encompass a wide range of tumors that develop in several areas of the $\mathrm{H} \& \mathrm{~N}^{1}$. They represent about $5 \%$ of all malignant tumors in the US and 17\% in Egyp. The median age of patients is 50 years with a male predominance of $3: 1$ and incidence mortality ratio of roughly $3: 1^{2}$. Radiation therapy (RT) plays an important role in the treatment of patients with H\&N cancer. Depending on the stage and location of malignancy (primary tumor, lymph node metastases), inevitably the salivary glands, oral mucosa, and jaws have to be included in the radiation treatment portals. As a result, changes induced by exposure to radiation occur in these tissues. The resulting sequel may cause substantial problems during and after RT and are major factors in determining the patient's quality of life ${ }^{3}$. Oral mucositis $(\mathrm{OM})$ is an inflammation of the mucosa of the mouth which ranges from redness to severe ulceration, also called stomatitis and it is a common complication of radio and chemotherapy occurring in about $60 \%$ of cancer patients. Symptoms of OM vary from pain and discomfort to an inability to tolerate food or fluids ${ }^{4}$. Mucositis may also limit the patient's ability to tolerate either Chemotherapy (CTH) or RT, so that it may interrupt treatment and thus limit the effectiveness of cancer therapy ${ }^{5}$.

OM usually develops within seven to fourteen days after RT or CTH is initiated. Mucositis secondary to radiation results from repeated tissue damage from multiple treatments. It begins to manifest at doses of 1000 to 2000 cGy (one to two weeks of conventionally fractionated therapy) and is limited to the field of radiation. Initial signs may include mucosal whitening due to transient hyper-keratinization followed by erythema, or erythema may occur first. Ulceration then occurs typically at doses above 3000 cGy. Following the end of radiation treatment, it requires three to six weeks for oral tissue to heal.

The cancer patient's risk of developing OM is highly variable. RT to the oral cavity is associated with different grades of occurrence. Virtually all patients who receive 5000 cGy or more will develop moderate to severe degree of $\mathrm{OM}^{6}$. 


Vol. 8 $\mid$ No. 3-4 $2012 \quad$ M. Abdelrahman et al.

LASER (Light Amplification by the Stimulated Emission of Radiation) is a form of phototherapy which involves the application of monochromatic light over biological tissue to elicit a biomodulative effect within that tissue. Low Power Laser Therapy (LPLT) has recently gained popularity, LPLT at adequate wave length, intensity and dose can accelerate tissue repair ${ }^{7}$. The use of LPLT appears to be a simple, non-traumatic technique for prevention and treatment of RT induced mucositis. The irradiation by LPLT corresponds to local application of high photon density monochromatic light source and was found to be effective in preventing and treating mucositis in H\&N cancer patients 5 . LPLT leads to activation of epithelial healing; it is useful in the treatment of mucositis of various origins ${ }^{8}$.

Aim of work:-This prospective phase II trial aiming at evaluation of feasibility \& tolerability of LPLT in the treatment of RT induced $\mathrm{OM}$ in $\mathrm{H} \& \mathrm{~N}$ cancer.

Patients \& methods Forty patients under RT at Kasr Alaini Center of Clinical Oncology \& Nuclear Medicine (NEMROCK)-Faculty of Medicine - Cairo University, were included in the study during the period from March to November 2009 fulfilling the following inclusion criteria:-

- Age ranged from 40-65 years old.

- All patients were pathologically proven to have squamous cell carcinoma of head and neck.

- All patients received radiotherapy on a post operative base except for radical nasopharyngeal cancer treatment.

- All patients were treated using conventional fractionation to a total dose of $50-60 \mathrm{~Gy} / 25$ 30 fractions/5-6weeks except for radical nasopharyngeal cancer treatment with a boost dose of $10 \mathrm{~Gy} / 5$ fractions/1week to the nasopharynx beyond the 60Gy, a dose we think it will not affect our study(away from oral mucosa).

- Any RTOG grade of OM.

- Patient informed written consent.

All patients received dental care before the start of $\mathrm{RT}$ and received routine medical care in the form of local antifungal and analgesics during the LASER treatment.

\section{Exclusion criteria:}

- Patients with double malignancy.

- Patients who had undergone previous head and neck radiation (Re-irradiation).

- Patients with severe collagen vascular disease.

All patients were planned by 2D planning. The LASER apparatus which used in this study was gallium arsenide (GA-AS) LTU-904 with power output $5 \mathrm{w}$ and pulse length 200 ns. The LASER unit infrared Gallium
Arsenide (GA-AS) LASER diode LTU-904: is a small hand held machine class I,LASER product under the existing requirement of United States of food and drug association regulation (The manual of LTU-904 Infrared Laser- Figure 1). The patients were given information about the treatment procedures, and laser device before the beginning of the treatment. Treatment with laser was being taken daily 5 days/week till the end of RT treatment with minimum treatment duration of 2 weeks and maximum treatment duration of 4 weeks. The patients were placed in sitting position with feet and head supported.The patients and the therapist were wearing black goggles for eye protection. Before the beginning of the session, the device was being checked. The laser probe was sterilized before and after every application with alcohol. Appropriate wave length (wave length of $904 \mathrm{~nm}$ ) had been selected. The probe was being directly in contact with the treated area. The session time was determined according to the patient's grade and affected site, with the application of laser irradiation for $1 \mathrm{~min}$ to each affected point. At the end of the session the device was being switched off and the area being treated was checked for swelling, redness or sores. Protective glasses (Figure 1) were worn by both the treating physician and the patient.

The mucositis grade was assessed using the Radiation Therapy Oncology Group (RTOG) assessment scale of OM which consists of 5 grades from 0 (no oral mucositis) to 4 (necrosis or deep ulceration present, with or without bleeding).

\section{Grade 0:}

No change over baseline

\section{Grade 1:}

May experience mild pain not requiring analgesic.

\section{Grade 2:}

Patchy mucositis that may produce inflammatory serosanguinous discharge, may experience moderate pain.

\section{Grade 3:}

Confluent fibrinous mucositis may include severe pain requiring narcotic.

\section{Grade 4:}

Ulceration, hemorrhage, or necrosis.

Data were statistically described in terms of range, mean \pm standard deviation (SD), median, frequencies (number of cases) and relative frequencies (percentages) when appropriate. All statistical calculations were done using computer programs Microsoft Excel version 7 (Microsoft Corporation, NY, USA) and SPSS version (Statistical 
Package for the Social Science; SPSS Inc., Chicago, IL, USA) statistical program for Microsoft Windows.

\section{RESULTS}

Forty cancer patients 20 males and 20 females suffering from OM participated in this study. The age of the patients ranged from 40 to 65 years with median of 54.5 years. Sixteen patients $(40 \%)$ were smokers and twenty four $(60 \%)$ were non-smokers. The numbers of cases with laryngeal carcinoma was 22 (55\%), the numbers of cases with nasopharyngeal carcinoma was 13 $(32.5 \%)$, and the numbers of cases with tongue cancer was $5(12.5 \%)$. The numbers of patients over 55 years were 18 patients $(45 \%)$ and the patients less than 55 years were $22(55 \%)$. The percentage of RTOG assessment scale grades pre treatment was $7.5 \%$ for grade I, 37.5\% for grade II, and 55\% for grade III. The RTOG assessment scale mean value pre treatment was $2.47 \pm 0.64$ as shown in (Table 1). There was a significant reduction in the mean RTOG assessment scale between pre and post treatment values by $54.65 \%$ from $2.47 \pm 0.64$ to $1.12 \pm 0.33$ (with $P$-value $=0.0001)$ as shown in (Table2)

\section{Univariate analysis}

There was no significant difference between male and female patients regarding site of tumor, age, pre treatment mucositis grade and mean RTOG assessment scale. There was only significant difference regarding smoking status ( $80 \%$ of males versus $0 \%$ of females were smokers, $P$-value $0.0001)$. There was a significant reduction in the value of mean RTOG assessment scale of male patients between pre and post treatment from $2.35 \pm 0.74$ to $1.15 \pm 0.36$ (51.06 $\%$ with $P$-value $=0.0001$ and in female patients from $2.6 \pm 0.5$ to $1.1 \pm 0.3(57.69 \%)$ with $P$-value $=0.0001$. the better effect seen in females (difference of $6.63 \%$ ) was statistically significant in the univariate analysis as $P$-value $=$ 0.003 as shown in (Table 3).

Patients were classified according to age into two groups, the first group over 55 years (18 patients) and the second group aged 55 years or younger ( 22 patients). There was no significant difference between both groups of age regarding smoking status, site of tumor, sex, pre treatment mucositis grades and mean RTOG assessment scale. There was a significant reduction of mean RTOG values pre and post treatment for old patients over 55 years of $52.04 \%$ with $P$-value $=0.0004$ and $56 \%$ for patients aged 55 years or younger with $P$-value $=0.0001$. The better improvement in young patients with a difference of $3.96 \%$ was statistically insignificant in the univariate analysis as with $P$-value $=0.194$ as shown in (Table 3 ).

There was no significant difference between smokers and non smokers regarding site of tumor, age, pre treatment mucositis grades and mean RTOG assessment scale. But male sex was predominant in smokers (80 $\%, P$-value 0.0001$)$, and female sex was predominant in non smokers $(100 \%, P$-value 0.0001$)$. There was a significant reduction in mean RTOG assessment scale pre and post treatment for smokers by $51.51 \%$ and by 56.58 $\%$ for non smokers with $P$-values $=0.0001$. The better improvement in non smokers by $5.07 \%$ was statistically significant in the univariate analysis as with $P$-value $=$ 0.008 as shown in (Table 3 ).

\section{Multivariate analysis:}

The effect of smoking \& sex was evaluated in a multivariate analysis \& showed that sex is the only statistically significant independent prognostic factors affecting reduction in the mean $\mathrm{RTOG}$ scale $(P$-value $=$ 0.045 ) while smoking showed no significant effect in the multivariate analysis $(P$-value $=0.132)$

\section{Toxicity}

Patients tolerated the LPLT treatment without any adverse effects or reaction.

Table 1: General characteristics of patients

\begin{tabular}{|c|c|c|c|}
\hline \multirow{2}{*}{ Character } & & \multicolumn{2}{|c|}{ Value } \\
\hline & & Number & $\%$ \\
\hline \multirow{2}{*}{ Sex } & Male & 20 & $50 \%$ \\
\hline & Female & 20 & $50 \%$ \\
\hline \multirow{2}{*}{ Smoking } & Smoker & 16 & $40 \%$ \\
\hline & Non smoker & 24 & $60 \%$ \\
\hline \multirow{3}{*}{ Site of tumor } & Larynx & 22 & $55 \%$ \\
\hline & Nasopharynx & 13 & $32.5 \%$ \\
\hline & Tongue & 5 & $12.5 \%$ \\
\hline \multirow{3}{*}{ Age } & $>55$ years & 18 & $45 \%$ \\
\hline & $<55$ years & 22 & $55 \%$ \\
\hline & Median age & \multicolumn{2}{|c|}{54.5} \\
\hline \multirow{3}{*}{$\begin{array}{l}\text { Pre treatment } \\
\text { mucositis } \\
\text { grades }\end{array}$} & Grade 1 & 3 & $7.5 \%$ \\
\hline & Grade 2 & 15 & $37.5 \%$ \\
\hline & Grade 3 & 22 & $55 \%$ \\
\hline \multicolumn{2}{|c|}{$\begin{array}{l}\text { Mean of RTOG assessment scale } \\
\text { pre treatment } \pm \text { SD }\end{array}$} & \multicolumn{2}{|c|}{$2.47 \pm 0.64$} \\
\hline
\end{tabular}

Table 2: RTOG assessment scale pre and post treatment for whole patients

\begin{tabular}{lcc}
\hline \multirow{2}{*}{ Total number of the patients } & \multicolumn{2}{c}{ RTOG assessment scale } \\
\cline { 2 - 3 } & Pre treatment & Post treatment \\
\hline Mean \pm SD & $2.47 \pm 0.64$ & $1.12 \pm 0.33$ \\
\hline Mean difference & 1.35 \\
\hline Percentage of improvement & $54.65 \%$ \\
$(P$-value $)$ & $(0.0001)$ \\
\hline
\end{tabular}

*SD: standard deviation, $P$ : probability 
Kasr-El-Aini Journal Of Clinical Oncology And Nuclear Medicine

Vol. 8 $\mid$ No. 3-4 $2012 \quad$ M. Abdelrahman et al.

Table 3: RTOG assessment scale pre and post treatment (univariate analysis)

\begin{tabular}{lcccccc}
\hline & \multicolumn{7}{c}{ RTOG assessment scale } \\
\cline { 2 - 8 } & Male & Female & $>\mathbf{5 5}$ years & $\leq \mathbf{5 5 y e a r s}$ & smokers & Non-smokers \\
\hline $\begin{array}{l}\text { Mean } \pm \text { SD } \\
\text { pre-treatement/post-treatement }\end{array}$ & $\begin{array}{l}2.35 \pm 0.74 / \\
1.15 \pm 0.36\end{array}$ & $\begin{array}{l}2.6 \pm 0.5 / \\
1.1 \pm 0.3\end{array}$ & $\begin{array}{c}2.4 \pm 0.7 / \\
1.16 \pm 0.38\end{array}$ & $\begin{array}{r}2.5 \pm 0.59 / \\
1.09 \pm 0.29\end{array}$ & $\begin{array}{c}2.31 \pm 0.7 / \\
1.12 \pm 0.34\end{array}$ & $\begin{array}{l}2.58 \pm 0.58 / \\
1.12 \pm 0.33\end{array}$ \\
\hline Mean difference & 1.5 & 1.2 & 1.27 & 1.4 & 1.19 & 1.46 \\
\hline $\begin{array}{l}\text { Percentage of improvement } \\
(P \text {-value })\end{array}$ & $51.06 \%$ & $57.69 \%$ & $52.04 \%$ & $56 \%$ & $51.51 \%$ & $56.58 \%$ \\
$P$-value & $(0.0001)$ & $(0.0001)$ & $(0.0004)$ & $(0.0001)$ & $(0.0001)$ & $(0.0001)$ \\
\hline
\end{tabular}

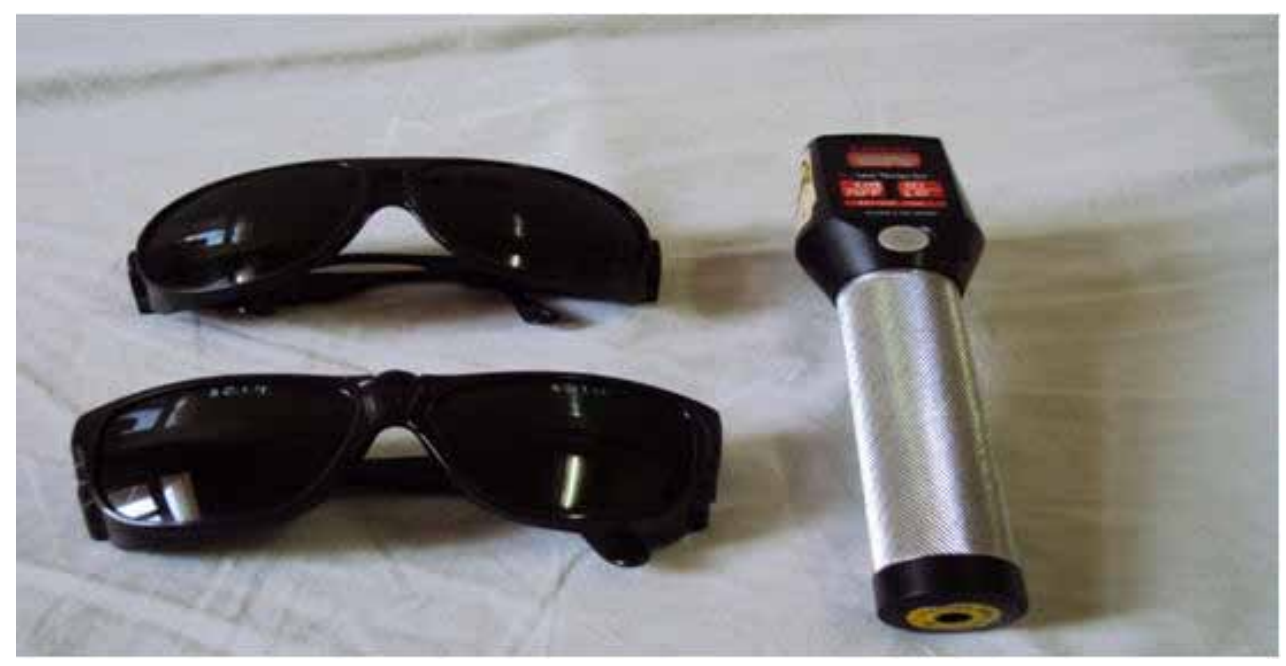

Figure 1: gallium arsenide (GA-AS) LTU- power output $5 \mathrm{w}$ and pulse length $200 \mathrm{~ns}$. The LASER unit infrared Gallium Arsenide (GA-AS) LASER diode LTU-904(to the right) \& the protective glasses (to the left).

\section{DISCUSSION}

To our knowledge, this is the first Egyptian study evaluating LPLT effect on treatement of RT induced OM. Patients in the present study developed oral mucositis after different durations (eg. Minimum of 10 days, and max of 4 weeks) from the start of RT and this is may be attributed to different tissue reactions and responses of each patient to RT, that is why the overall duration of treatment for each patient varied from one to another according to the time at which oral mucositis started and the grade of oral mucositis being treated.

In the current study the collected data were statistically analyzed and there was a significant difference between pre and post treatment values of RTOG assessment scale, for all patients who participated in the study. The percentage of improvement was $54.65 \%$ \& this agree with the results of Arun et al., who emphasized that LPLT was found effective in preventing and treating mucositis in $\mathrm{H} \& \mathrm{~N}$ cancer patiens. At the completion of
RT. The mucositis grade was significantly $(P<0.001)$ lower in the study group than in control group 5 . Mucositis grade was $1.72 \pm 0.67$ in the study group and $3.32 \pm 0.69$ in control group, and the patients tolerated LASER treatment without any adverse effect or reactions.

This agreed also with Antunes et al., who concluded that LPLT is efficient in the treatment of oral mucositis because even in patients with OM grade 4 the healing time of ulcers was on average 6 days and the patients did not mention any uncomfortabe sensation while the LASER was being applied ${ }^{9}$.

In the current study, the percentage of improvement in male patients was $51.06 \%$, with $P$-value of (0.0001). In female patients, the percentage of improvement was $57.69 \%$, with $P$-value of $(0.0001)$. The better improvement in female patients with a difference of $6.63 \%$ was statistically significant in the multivariate analysis $(P$-value $=0.045)$. This contradicted to the data of Engeland et al., 2006 who demonstrated a male 
advantage in healing rates of oral mucosal wounds and that older women may be at the highest risk for delayed healing following oral or mucosal surgery or injury ${ }^{10}$.

In the current study concerning the effect of age on patient improvement, the percentage of improvement for patients over 55 years between pre and post treatment values was $52.04 \%$, where $P$-value was (0.0004). For patients aged 55 years or less, the percentage of improvement between pre and post treatment values was $56 \%$, where $P$-value was $(0.0001)$. The better improvement in younger patients with a difference of 3.96 $\%$ was statistically insignificant with $P$-value $=0.194$. This agreed with Sonis, 2000 who emphasized that healing of oral mucositis is more rapid in younger age groups ${ }^{11}$.

In the current study concerning the effect of smoking on the patients improvement, percentage of improvement of smoker patients (males only as there was no female smokers) was $51.51 \%$, while percentage of improvement of non smoker patients (males and females) was $56.58 \%$. The better improvement in non smoker patients by $5.07 \%$ was statistically significant only in the univariate analysis with $P$-value $=0.008$. This agreed with Indian, 2008 who confirmed that the association between smoking and delayed healing of oral tissues is evident ${ }^{12}$.

\section{CONCLUSION}

LPLT is a feasible well tolerated treatment for RT induced OM with better results seen in non smokers $\&$ females with female sex was the only independent prognostic factor in a multivariate analysis. Further phase III study is recommended.

\section{REFERENCES}

1. Kutler DI, Wreesmann VB, Goberdhan A, Ben-Porat L, Satagopan J, Ngai I, et al. Human papillomavirus DNA and p53 polymorphisms in squamous cell carcinomas from Fanconi anemia patients. J.Natl.Cancer Inst. 2003;95(22):1718-21.
2. El-bolkainy M. Topographic pathology of cancer. Cairo University: National cancer institute; 2008.

3. Vissink A, Jansma J, Spijkervet FK, Burlage FR, Coppes RP. Oral sequelae of head and neck radiotherapy. Crit.Rev. Oral Biol.Med. 2003;14(3):199-212.

4. Bensadoun RJ, Magné N, Marcy PY, Demard F. Chemotherapy- and radiotherapy-induced mucositis in head and neck cancer patients: New trends in pathophysiology, prevention and treatment. Eur.Arch. Otorhinolaryngol. 2001;258(9):481-7.

5. Maiya Arun G, Sagar MS, Fernandes D. Effect of low level helium-neon (He-Ne) laser therapy in the prevention \& treatment of radiation induced mucositis in head \& neck cancer patients. Indian J.Med.Res. 2006;124(399):402.

6. Epstein JB, Schubert MM. Oropharyngeal mucositis in cancer therapy. Review of pathogenesis, diagnosis and management. Oncology 2003;17(12):1767-1779; discussion 1779-82, 1791-2.

7. Georgescu R, Iacob M, Suciu D. Application of self made scanned laser system for low level laser therapy in dermatological and rheumatic affections. J.optoelectronics Adav.mater. 2005;7(6):2887-94.

8. Bensadoun RJ, Le Page F, Darcourt V, Bensadoun F, Ciais $\mathrm{G}$, Rostom YA, et al. [Radiation-induced mucositis of the aerodigestive tract: Prevention and treatment. MASCC/ ISOO mucositis group's recommendations]. Bull.Cancer 2006;93(2):201-11.

9. Antunes H, De Azevedo AM, Da Silva Bouzas LF, Adão C, Pinheiro CT, Mayhe R, et al. Low-power laser in the prevention of induced oral mucositis in bone marrow transplantation patients: A randomized trial. Blood 2007;109:2250-5.

10. Engeland CG, Bosch JA, Cacioppo JT, Marucha PT. Mucosal wound healing: the roles of age and sex. Arch. Surg. 2006;141(12):1193-1197; discussion 1198.

11. Sonis ST. Mucositis as a biological process: A new hypothesis for the development of chemotherapyinduced stomatotoxicity. Oral Oncol. 1998;34(1):39-43.

12. Balaji SM. Tobacco smoking and surgical healing of oral tissues: A review. Indian J.Dent.Res. 2008; 19(4):344-8. 